\title{
Microsurgical Resection of Tuberculum Sellae Meningioma via Pterional Craniotomy with Extradural Anterior Clinoidectomy and Optic Unroofing
}

\author{
Ihsan Dogan ${ }^{1}$ Melih Ucer ${ }^{1}$ Mustafa Kemal Başkaya ${ }^{1}$ \\ ${ }^{1}$ Department of Neurological Surgery, University of Wisconsin School \\ of Medicine and Public Health, Madison, Wisconsin, United States \\ J Neurol Surg B 2018;79(suppl S2):S218. \\ Address for correspondence Mustafa Kemal Başkaya, MD, \\ Department of Neurological Surgery, University of Wisconsin School \\ of Medicine and Public Health, 600 Highland Avenue K4/8 CSC, \\ Box 8660, Madison, WI 53792, United States \\ (e-mail: m.baskaya@neurosurgery.wisc.edu).
}

\begin{abstract}
Keywords

- skull base

- pterional approach

- tuberculum sellae meningioma

- anterior clinoidectomy

Microsurgical treatment of suprasellar tumors, in particular tuberculum sellae meningiomas, poses significant challenge. These tumors are surrounded by vital neurovascular structures, such as optic apparatus, pituitary stalk, internal carotid artery and its branches, and anterior cerebral arteries. In large and complex cases, early identification and decompression of these structures may facilitate safer dissection and resection. Therefore, extradural anterior clinoidectomy with optic unroofing facilitates the internal carotid artery exposure and optic nerve decompression. In this video, we describe a 37-year-old female patient who presented with new onset of severe headaches. On visual examination, she was found to have bitemporal visual defects. MRI scan of the head showed a large, approximately $3 \mathrm{~cm}$ suprasellar tumor consistent with tuberculum sellae meningioma. She underwent surgical resection via pterional craniotomy with extradural anterior clinoidectomy and optic unroofing. Microsurgical gross total resection was achieved and histopathology was WHO grade II meningioma. She had an uneventful postoperative course and visual field examination improved significantly. In this video, surgical technique in performing extradural anterior clinoidectomy and optic unroofing and steps of microsurgical resection are demonstrated.

The link to the video can be found at: https://youtu.be/oPZ8NTyvxjc.
\end{abstract}

received

October 17, 2017

accepted

November 29, 2017

published online

January 16, 2018
DOI https://doi.org/

10.1055/s-0037-1620254. ISSN 2193-6331. (c) 2018 Georg Thieme Verlag KG

Stuttgart · New York
License terms

(c) (i) $\ominus$ (요 